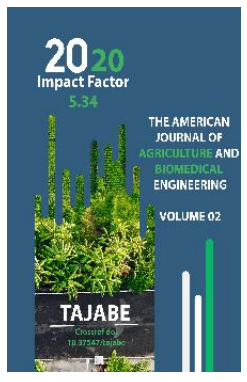

Journal Website: http://usajournalshub.c om/index,php/tajabe

Copyright: Original content from this work may be used under the terms of the creative commons attributes 4.0 licence.

\section{Quarantine Requirements For The Use Of Biological Method Of Quaranty Pest Combtok Worm}

\author{
Jakhongir Ergashevich Alimdjanov \\ Tashkent State Agrarian University, Tashkent, Uzbekistan. \\ Otabek Abdushukirovich Sulaymonov \\ Scientific Center For Plant Quarantine Of The State Plant Quarantine Inspection Under The \\ Cabinet Of Ministers Of The Republic Of Uzbekistan, Tashkent, Uzbekistan
}

\title{
ABSTRACT
}

At present, in developed countries, including Uzbekistan, the system of coordinated control in the fight against agricultural pests is widely used. Its essence is to protect the crop by using agrotechnical, mechanical, physical methods of pest control, mainly using methods of biological control, which are harmless to the environment, humans and organisms, and the use of chemical methods as an exception when necessary. In recent years, the ecological situation in rural areas has been improved as a result of the use of a combined protection system in cotton, wheat and other crops, ie the method of biological control, which is its core.

\section{KEYWORDS}

Harm, morphology, larva, development, biology, control measures, entomophage.

\section{INTRODUCTION}

The advantage of the biological control method is that the cultivation of agricultural products without the use of chemicals, ie pesticides, ensures the purity of the environment, as well as the preservation of many species of living things that occur in nature.
Researchers of the Scientific Center for Plant Quarantine under the State Inspectorate for Plant Quarantine under the Cabinet of Ministers of the Republic of Uzbekistan are conducting in-depth study.

In particular, the comstock worm (pseudococcus comstocki kuw) is a dangerous quarantine pest of orchards, subtropical crops 
and various agricultural crops. Its ancient homeland is Japan and China, and entomologist S. Kuvan described the worm in 1902 and named it Comstock Worm in honor of the American entomologist Comstock. Currently, this pest is widespread in many countries in Asia, Africa, Australia, America and Europe. In particular, it is widespread in the Central Asian Republics, Georgia, Armenia, Azerbaijan, Russia and Ukraine.

The Comstock worm was first detected in Uzbekistan in August 1939 at the Jarariq Experimental Farm of the Central Asian Silk Institute near Tashkent in large-leaved mulberry seedlings imported from Japan.

\section{MATERIALS AND METHODS}

Comstock worms infect more than 300 different plants. Pomegranate, quince, apple, pear, peach, as well as mulberries from fruit trees cause severe damage. They settle in large colonies on the trunk, branches and leaves of the tree and absorb the sap of the tree, drying out its medicine and weakening its growth. In severely damaged trees, swellings appear, young branches dry out and the leaves fall off. Comstock worm also penetrated into the soil to a depth of $5-6 \mathrm{~cm}$, damaging the plant, flowers, fruits, and also sucked the upper part of the roots. Occurs in some cases at a depth of up to $40 \mathrm{~cm}$. The worms usually feed along the veins in the lower part of the leaf.

Comstock worms cause great damage, especially to mulberry trees. Damaged mulberry leaves turn yellow and fall off into a haze. Mulberry leaves contaminated with Comstock worm waste are considered harmful to silkworms. A cup of pomegranate fruit also helps in the good development of the comstock worm and its eggs and leads to a sharp decrease in productivity.
It is very important to develop and use effective biological control measures against Comstock worms. To this end, the Plant Quarantine Research Center conducted experiments to increase the entomophagous Pseudaphycus (Pseudaphycus malinus), one of its effective cousins, and its use in pest control.

Pseudophycus is an insect with a yellow body with a bell-shaped white spot, the body size of the female is about $0.75-1.0 \mathrm{~mm}$. The top of the head and chest are yellow. The mustache is brown, the tip is white with a beak. The front wing is clear, the middle is slightly blurred. The appearance of both sexes is the same, but the body size of male individuals is slightly smaller.

The pseudoficus lives 5 to 12 days, laying an average of 60 to 150 eggs during its lifetime. The comstock lays its eggs inside the worm's body. The egg looks like a white dumbbell. Pseudophicus paralyzes more than 20 comstock worms and develops from 2 to 25 pseudophicus larvae in the body of one comstock worm. The whole developmental stage of pseudophic entomophagy takes place inside the worm's body. Mature insects gnaw on the worm's shell and fly out. From each worm, 7-10 mature insects develop and fly, which in turn infect and kill other worms. Pseudophyxus causes comstock worms of all ages. Infected comstock worms continue to feed for the first few days and their appearance is no different from healthy worms. After 5-6 days, they lose their waxy crust, stop feeding and become restless. It accumulates in secluded places, bark cracks, pits, between the soil, around the roots of trees, where it perishes and takes the form of a mummy. The mummy is oval in shape, shiny yellow in its new state, then begins to darken. 
The pseudophycus becomes a fungus in the mummy (the body of a dead comstock worm).

\section{PURPOSE OF THE RESEARCH}

A single mummy microscope propagated in the biolaboratory of the Scientific Center for Plant Quarantine revealed the presence of 15 to 18 mature insects of pseudophycus. They were arranged in 2 rows parallel to the body of the comstock worm. We separated a pseudophyxus from a mummy and observed

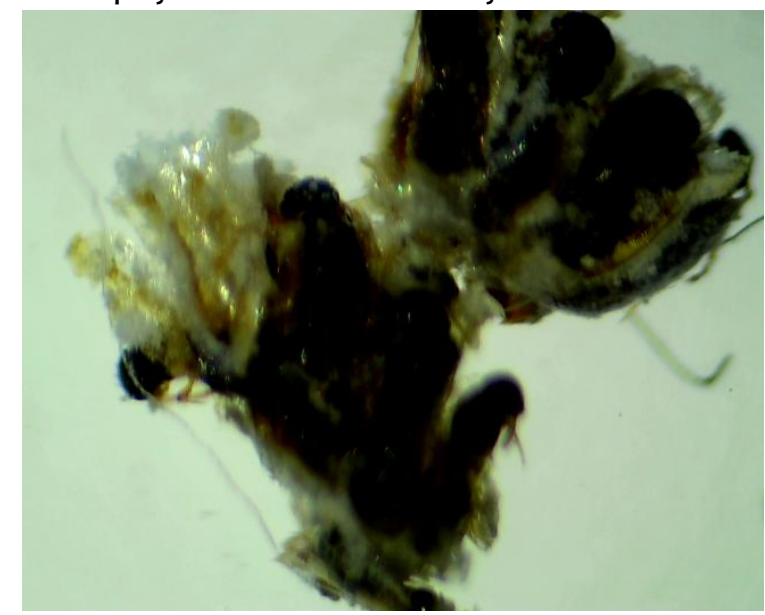

Pseudoficus entomophagy developing within the mummy

In our observations, Pseudophicus entomophagy has been shown to infect its morphology. The appearance of the pseudoficus was brown, and the body consisted of the head, chest, and abdomen. He had a pair of whiskers on his head, and at each joint of his mustache was a thorn-like growth. The thorax had 3 pairs of legs and 1 pair of wings, and the wings were found to be transparent in appearance and the abdomen to be oval-oblong in shape.

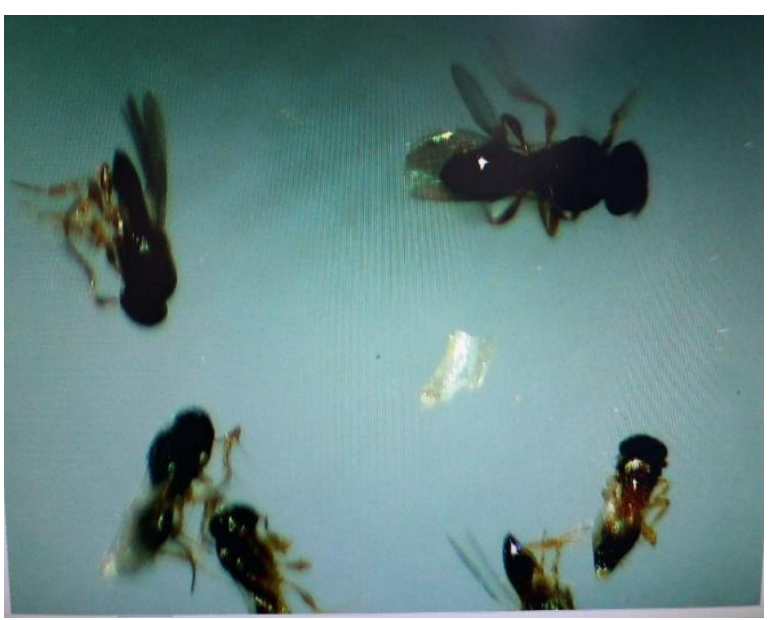

A mature insect of the pseudophycus entomophagy

comstock worms of all ages and to damage its eggs as well. 


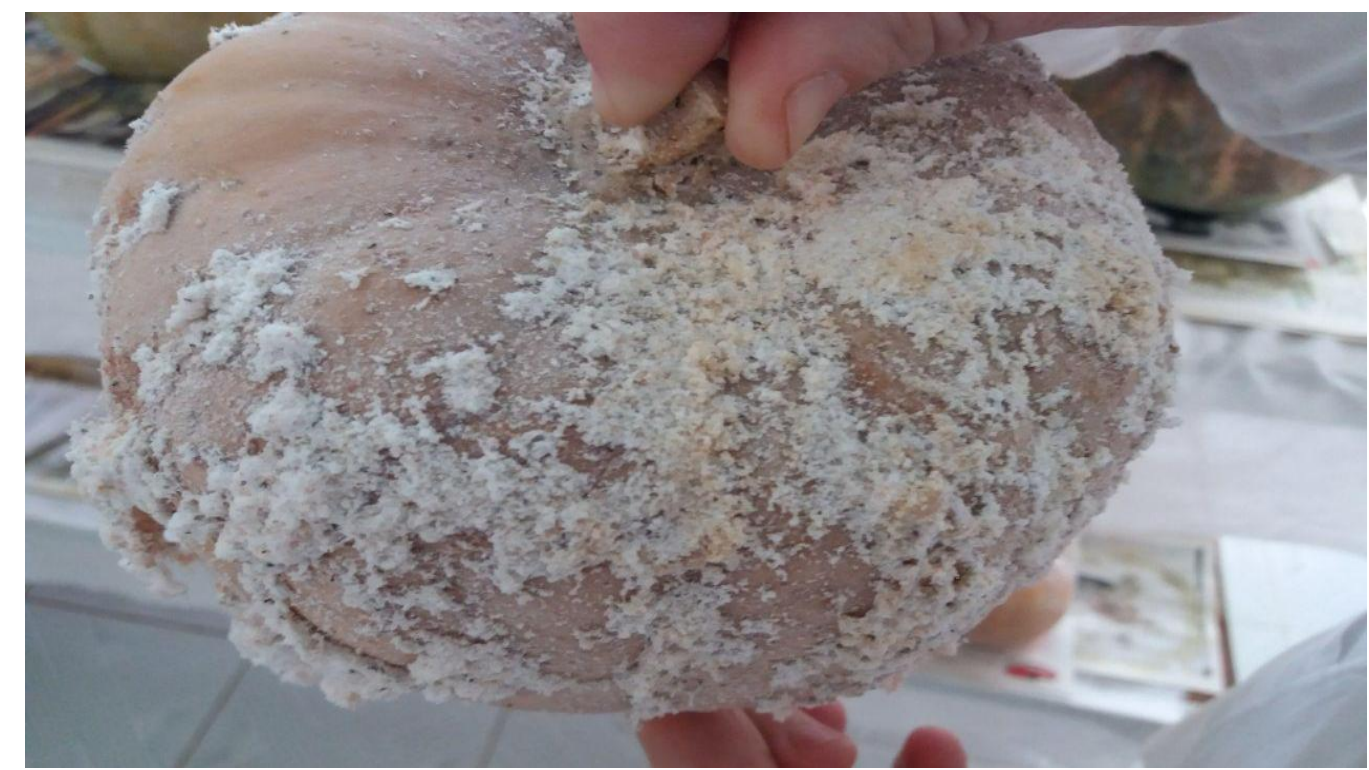

\section{Infection of pseudoficus with comstock worm eggs growing in pumpkin fruit}

In this picture we can see that the eggs of the comstock worm, which is propagated in the pumpkin fruit, are infected with pseudoficus. The eggs of the comstock worm infested with pseudophycus are separated from the waxcovered sac and remain as a powder. When the infected comstock worm eggs are viewed under a microscope, we can see that the internal fluid of the egg has emptied and the outer and inner parts have darkened and lost their transparent state. The outside of the undamaged comstock worm eggs is yellow, the inside is covered with a turbid liquid, and is transparent in appearance.
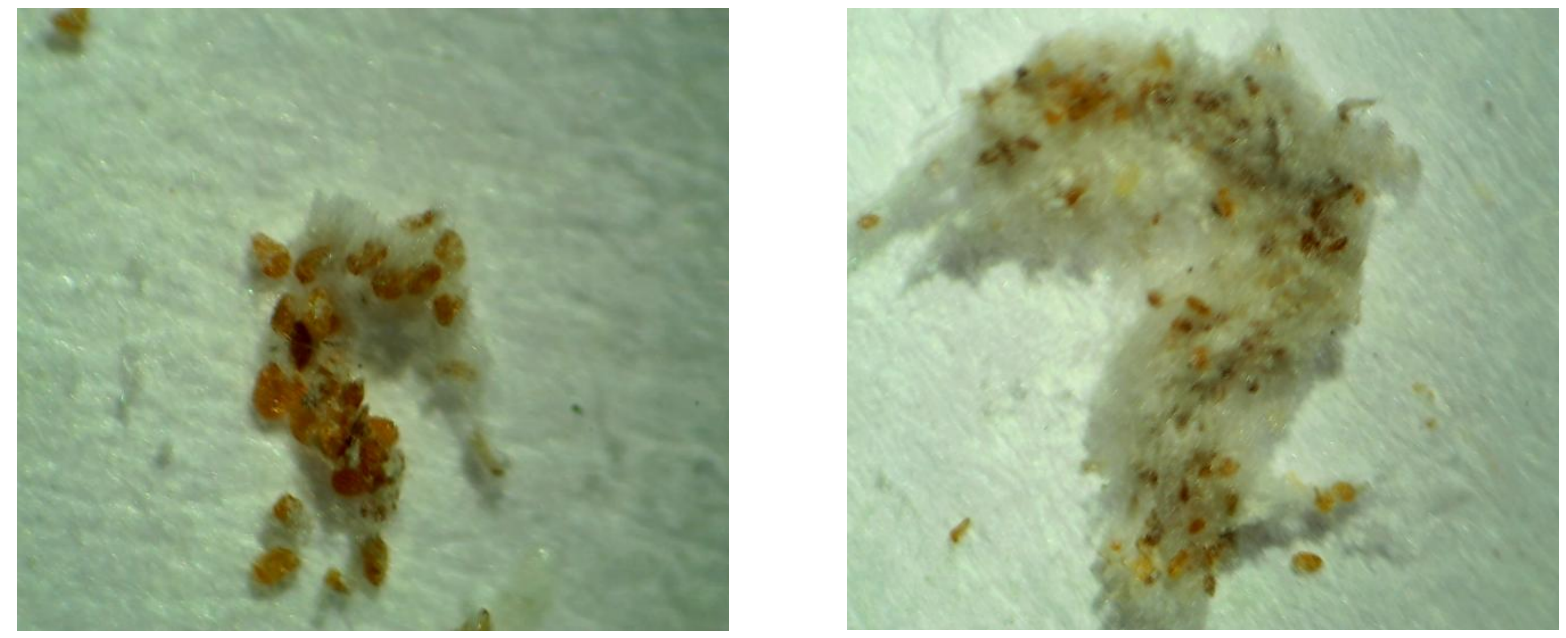

Microscopic view of comstock worm eggs infested by pseudoficus 
In the biolaboratory, comstock worms infested with pseudoficus are made of special paper to make mummies. Infected comstock worms accumulate in the larvae and take the form of mummies. When we observed mummies collected on special parchment papers under a microscope, it was observed in our research that comstock worms of all ages have become

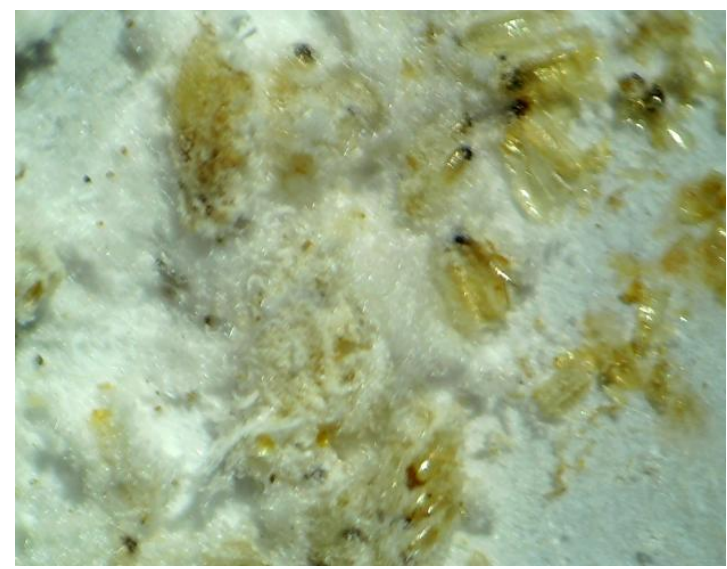

Pseudoficus entomophagy is fully developed in mummies, microscopic view of the emptied state of mummies

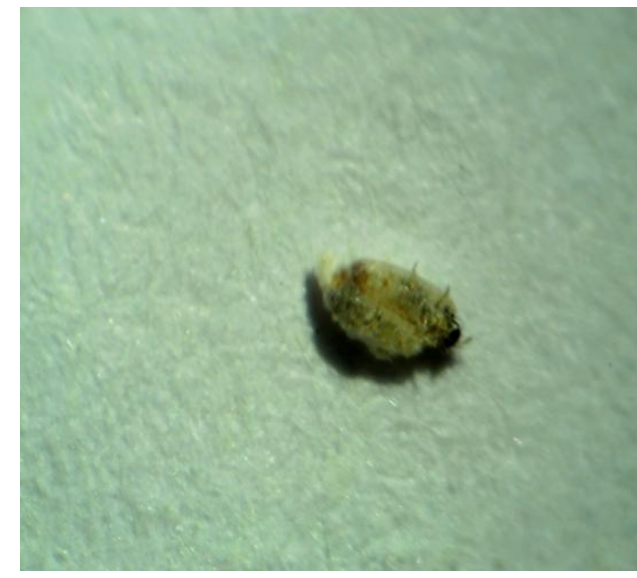

Pseudoficus infection of comstock worms from 1 to 2 years of age (front and back view) mummies and that many pseudoficus entomophagous are developing in these mummies. Among them there are many mummies with hollow skin. This condition means that the pseudophycus has developed and come out of the mummy.

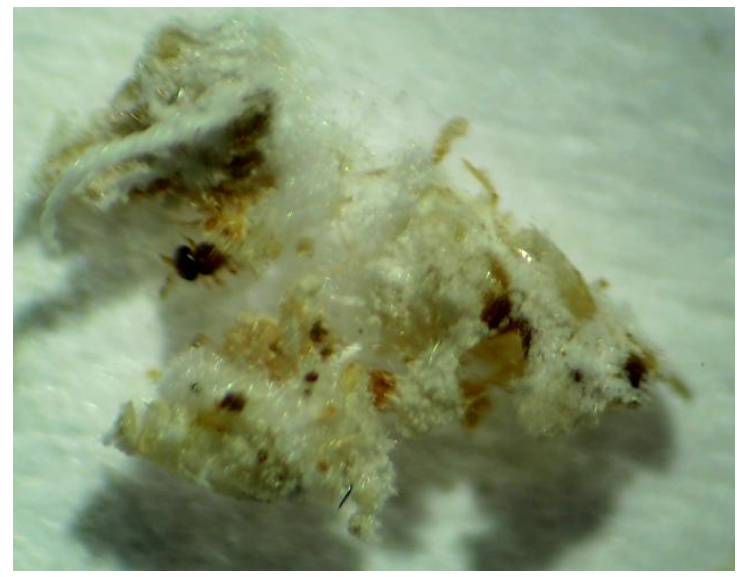

Pseudoficus entomophagy isolated from mummy

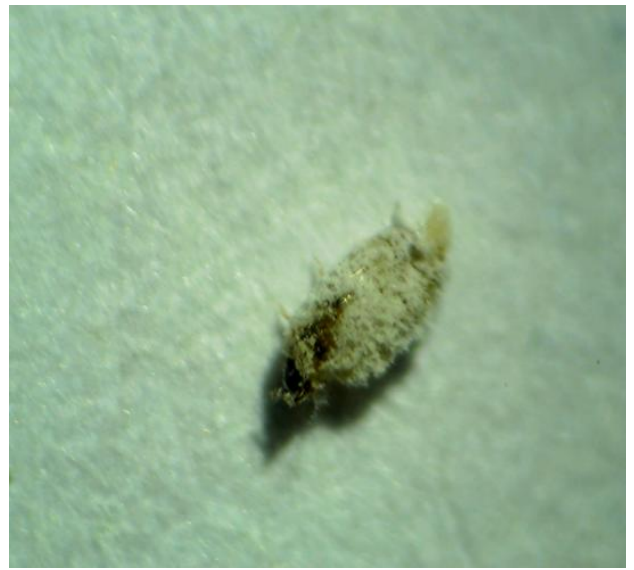



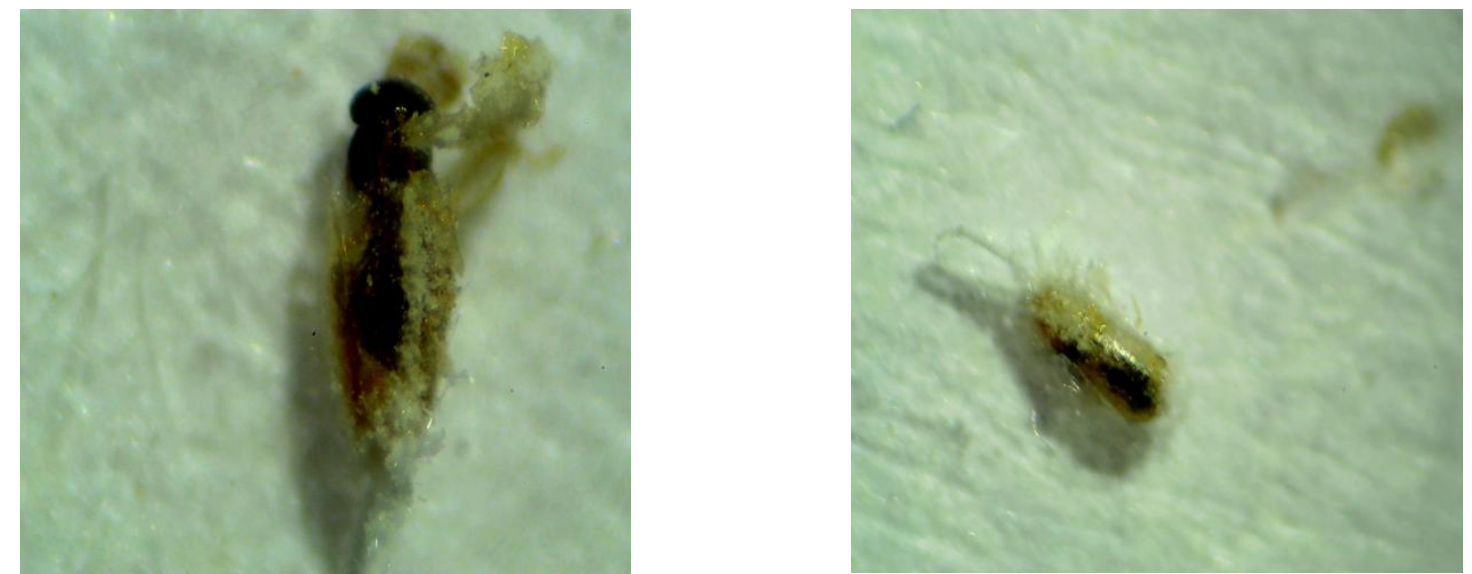

An advanced state of a single entomophage in the body of a fully developed comstock worm

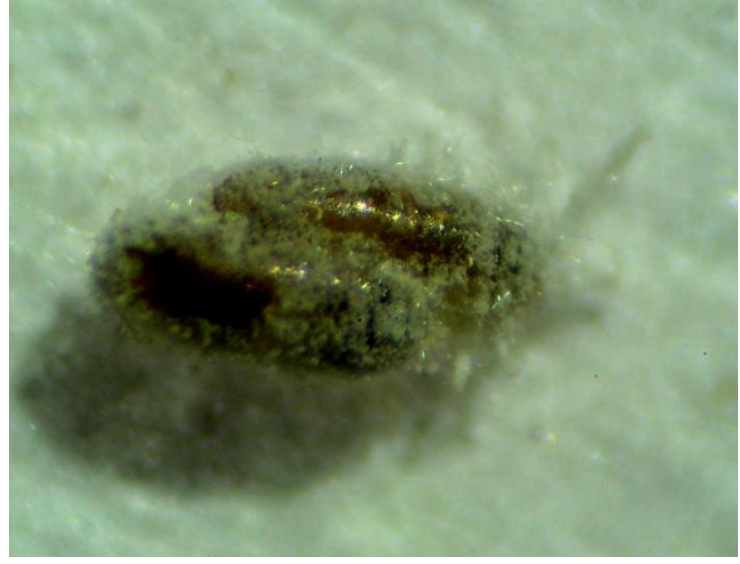

The dome-shaped state of two entomophages developing in the body of the Comstock worm

Among the mummies we observed under a microscope, we encountered an entomophagous larva that had just begun to develop. It looked like a dome and was covered in liquid. In another mummy, the entomophages were composed of several

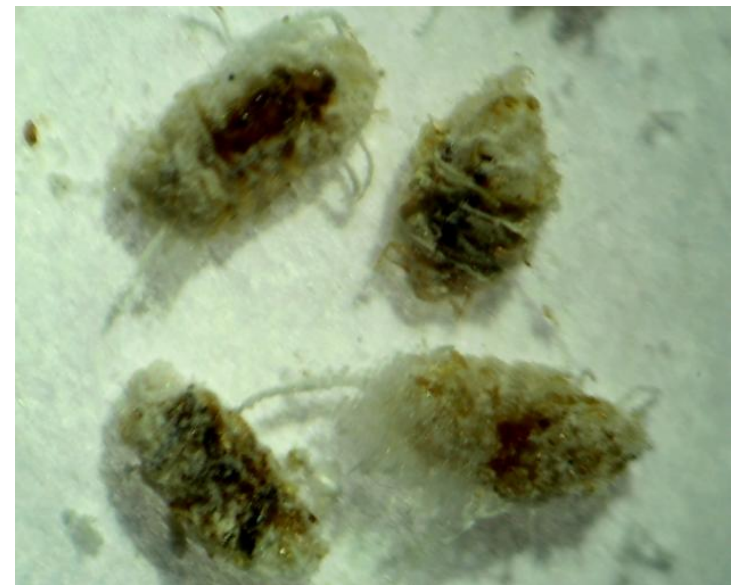

Microscopic view of mummies

fungi, which were yellowish-red in appearance. This means that the inner fluid of the fungus is filled with a harder substance and turns into an adult pseudophyxus (imago). 


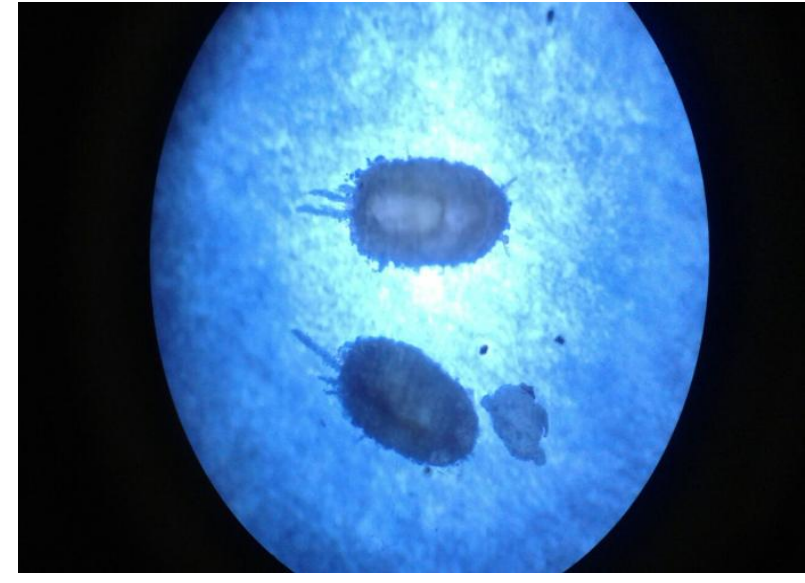

Entomophagous larva, which has just begun to develop in the mummy

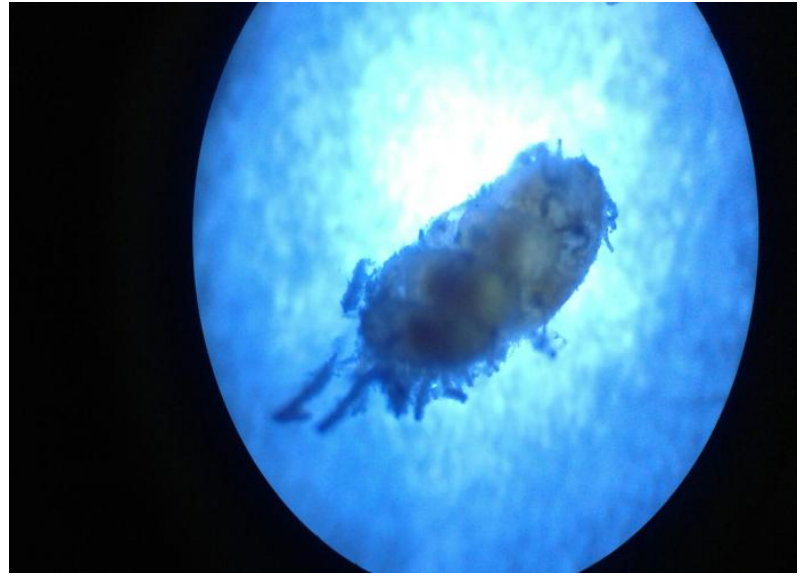

Growing inside the fungus entomophagous larvae

Efficacy of pseudophicus tekinhorus when applied in different proportions against comstock worm larvae

\begin{tabular}{|c|c|c|c|c|}
\hline \multirow{2}{*}{ № } & \multirow{2}{*}{$\begin{array}{c}\text { Experiment } \\
\text { options }\end{array}$} & \multirow{2}{*}{ Repetition } & \multicolumn{2}{|c|}{$\begin{array}{c}\text { Number of Comstock larvae } \\
\text { and pseudoficus (pcs.) }\end{array}$} \\
\hline & & & larva & mummy \\
\hline \multirow{4}{*}{1.} & \multirow{4}{*}{$\begin{array}{c}\text { Total when the } \\
\text { ratio of } \\
\text { pseudophycus } \\
\text { comstock worm } \\
\text { larvae is set at } \\
1: 10\end{array}$} & 1 & 110 & - \\
\hline & & 2 & 68 & - \\
\hline & & 3 & 101 & - \\
\hline & & average & 279 & - \\
\hline \multirow{4}{*}{2.} & \multirow{4}{*}{$\begin{array}{l}\text { Total when the } \\
\text { ratio of } \\
\text { pseudophycus } \\
\text { comstock worm }\end{array}$} & 1 & 84 & - \\
\hline & & 2 & 52 & - \\
\hline & & 3 & 61 & - \\
\hline & & average & 197 & - \\
\hline
\end{tabular}


The American Journal of Agriculture And Boimedical Engineering (ISSN - 2689-1018)

Published: August 30, 2020 | Pages: 114-123

Doi: https://doi.org/10.37547/tajabe/Volume02Issueo8-13

\begin{tabular}{|c|c|c|c|c|}
\hline & $\begin{array}{c}\text { larvae is set at } \\
1: 15\end{array}$ & & & \\
\hline \multirow{4}{*}{3.} & \multirow{4}{*}{$\begin{array}{c}\text { Total when the } \\
\text { ratio of } \\
\text { pseudophycus } \\
\text { comstock worm } \\
\text { larvae is set at } \\
\text { 1:20 }\end{array}$} & 1 & 89 & - \\
\hline & & 2 & 54 & - \\
\hline & & 3 & 75 & - \\
\hline & & average & 218 & - \\
\hline \multirow{4}{*}{4.} & \multirow{4}{*}{ Total control } & 1 & 96 & - \\
\hline & & 2 & 57 & - \\
\hline & & 3 & 83 & - \\
\hline & & average & 236 & - \\
\hline
\end{tabular}

\begin{tabular}{|c|c|c|c|}
\hline \multicolumn{3}{|c|}{$\begin{array}{c}\text { Number of Comstock larvae and } \\
\text { pseudoficus (pcs.) }\end{array}$} & \multirow{2}{*}{$\begin{array}{c}\text { Efficacy of } \\
\text { pseudoficus free } \%\end{array}$} \\
\hline $\begin{array}{c}\text { put } \\
\text { pseudophicus }\end{array}$ & larva & $\begin{array}{c}\text { mummified } \\
\text { pupae }\end{array}$ & \\
\hline 11 & 26 & 84 & 76,36 \\
\hline 7 & 8 & 60 & 88,23 \\
\hline 10 & 2 & 99 & 98,02 \\
\hline 28 & 36 & 243 & 87,1 \\
\hline 6 & 12 & 72 & 85,71 \\
\hline 3 & 11 & 41 & 78,85 \\
\hline 4 & 12 & 49 & 80,33 \\
\hline 13 & 35 & 162 & 82,23 \\
\hline
\end{tabular}




\begin{tabular}{|c|c|c|c|}
\hline 4 & 23 & 66 & 74,16 \\
\hline 3 & 11 & 43 & 79,63 \\
\hline 4 & 24 & 51 & 68,0 \\
\hline 11 & 58 & 160 & 73,39 \\
\hline- & 96 & - & - \\
\hline- & 57 & - & - \\
\hline- & 81 & - & - \\
\hline- & 234 & - & - \\
\hline
\end{tabular}

\section{RESULTS AND CONCLUSIONS}

The ratio of entomophagous host (comstock worm) in the fight against pseudophyxus comstock worm is 1:10; Tested under laboratory conditions at 1:15 and 1:20 ratios. According to the test results, pseudoficus and comstock worm 1:10; When applied at a ratio of 1:15, it was observed that the number of pests decreased by 87,1 and $82,23 \%$ over 15 days under laboratory conditions. At a ratio of 1:20, it decreased by $73,39 \%$ compared to the control option in 15 days. From the results obtained, it can be concluded that high efficiency in pest control is achieved if the pseudoficus master ratio is applied in the ratios of 1:10 and 1:15.

The study of the morphology and bioecology of pseudophicus entomophagy, a relative of the comstock worm, which is an internal quarantine pest in the Republic of Uzbekistan, has led to the conclusion that the survival, reproduction and distribution of these natural insects are interrelated. It should be noted that the large-scale organization of entomophagous breeding in biolaboratory conditions, the study of other new species of entomophagous breeding methods in the fight against natural predators remains a requirement of today.

\section{REFERENCES}

1. Anorbaev A.R., Boltaev B.S., Kamilov Sh.G., Nuraliev Kh.Kh. "Measures to combat pests of agricultural crops" Tashkent-2016.

2. Metlitsky O.Z. System of protection of apple and pear // Protection and quarantine of plants. - 2003. - No. 6.-C. 44-47.

3. Murodov BE, Yakhoev Zh.N. Quarantine pests of internal quarantine of the Republic of Uzbekistan // Education and science in Russia and abroad. - 2017. - No. 3 (32). FROM. 32-36. 
4. Murodov B.E., Sulaymonov O.A., Yakhyoyev J.N. Harm of quarantine pests of the internal quarantine of the republic of Uzbekistan / Proceedings of 2nd Online International Multidisciplinary Scientific Conference on Innovative Technology Organized by Novateur Publications, India July 25th, - 2020. - P. 13-18.

5. Alimjanov Zh.E. Quarantine pest comstock worm / International science-practical conference. London, Great Britain. - 2019. - P. 11-14.

6. O.Sulaymonov, Q.Bababekov, D.Dusmatova, G. Dusmuradova. "Guidelines for the reproduction of entomophagous pseudophycus (Pseudaphycus malinus gah.) Against the Comstock quarantine pest in the laboratory." Tashkent - 2019

7. O.A Sulaymonov, K. Bobobekov, D.T Dusmatova, J.N Yahyoev "Quarantine pest - Comstock worm (Pseudococcus comstocki Kuw.) And measures to combat it." Tashkent - 2019

8. Yaxontov V.V. "Pests and control of Central Asian agricultural plants and products." Tashkent - 1961. 